Hepp, M., L. Ware, H. van Oort, S. M. Beauchesne, J. M. Cooper, and D. J. Green. 2018. Postfledging survival and local recruitment of a riparian songbird in habitat influenced by reservoir operations. Avian Conservation and Ecology 13(1):12. https://doi.org/10.5751/ACE-01190-130112 Copyright (C) 2018 by the author(s). Published here under license by the Resilience Alliance.

\title{
Postfledging survival and local recruitment of a riparian songbird in habitat influenced by reservoir operations
}

\author{
Matthew Hepp ${ }^{1}$, Lena Ware ${ }^{1}$, Harry van Oort ${ }^{2}$, Suzanne M. Beauchesne ${ }^{3}$, John M. Cooper ${ }^{3}$ and David J. Green ${ }^{1}$ \\ ${ }^{1}$ Centre for Wildlife Ecology, Department of Biological Sciences, Simon Fraser University, Burnaby, British Columbia, Canada, \\ ${ }^{2}$ Cooper Beauchesne and Associates Ltd., Revelstoke, British Columbia, Canada, ${ }^{3}$ Cooper Beauchesne and Associates Ltd., \\ Qualicum Beach, British Columbia, Canada
}

\begin{abstract}
The impact of anthropogenic activities on breeding bird populations are typically assessed using nest success despite the importance of the postfledging period and juvenile survival for the population dynamics of many birds. Using a combination of radio telemetry data collected between 2012 and 2014, and long-term monitoring data collected between 2005 and 2016, we evaluated whether postfledging survival of Yellow Warblers (Setophaga petechia) is affected when their riparian nesting habitat becomes inundated by the Upper Arrow Lakes Reservoir in the Columbia River Valley near Revelstoke, British Columbia, Canada. Thirty-eight percent of radiotagged fledglings $(n=26)$ survived for at least 21 days after leaving the nest. Radio-tagged birds that fledged from nests in territories that were inundated by water tended to be have lower survival than those that fledged from nests in territories that were not inundated by water. Local recruitment was low $(6.4 \%, \mathrm{n}=438)$. Local recruitment was nevertheless positively affected by nestling condition prior to fledging. Fledglings from territories that were not inundated by water also tended to be more likely to recruit locally than those that fledged from territories that were inundated by water. In both cases, we estimated that reservoir operations that flooded habitat reduced postfledging survival or local recruitment by approximately $50 \%$. Our study emphasizes the importance of considering the postfledging period when developing mitigation measures or management plans aimed at minimizing the impact of anthropogenic activities on bird populations.
\end{abstract}

\section{Survie des jeunes après l'envol et recrutement local d'un passereau ripicole nichant dans un habitat touché par la régulation du niveau d'eau d'un réservoir}

RÉSUMÉ. Les impacts qu'ont les activités anthropiques sur les populations d'oiseaux nicheurs sont habituellement évalués à partir du succès de nidification, malgré l'importance de la période suivant l'envol des jeunes et la survie juvénile dans la dynamique de population de nombreux oiseaux. En combinant des données de radiotélémétrie obtenues entre 2012 et 2014 et des données provenant d'un suivi réalisé de 2005 à 2016, nous avons évalué dans quelle mesure la survie après l'envol des jeunes de Paruline jaune (Setophaga petechia) était affectée lorsque leur habitat de nidification se trouve inondé par le réservoir Upper Arrow Lakes dans la vallée du fleuve Columbia près de Revelstoke, Colombie- Britannique, Canada. Trente-huit pourcent des jeunes munis d'un émetteur $(\mathrm{n}=26)$ ont survécu au moins 21 jours après avoir quitté le nid. La survie des jeunes ayant pris leur envol de nids situés sur des territoires ayant été inondés était généralement plus faible que celle des oiseaux ayant pris leur envol de nids situés sur des territoires n'ayant pas été inondés. Le recrutement local était faible $(6,4 \%, n=438)$. Néanmoins, le recrutement local était positivement lié à la condition des jeunes avant l'envol. Les jeunes ayant pris leur envol dans les territoires non inondés étaient aussi plus susceptibles de revenir nicher localement que ceux ayant pris leur envol dans les territoires inondés. Dans les deux cas, nous avons estimé que la régulation du niveau d'eau du réservoir ayant mené à l'inondation de l'habitat avait entraîné la réduction de la survie après l'envol ou du recrutement local par 50 \% environ. Notre étude souligne l'importance de considérer la période suivant l'envol des jeunes au moment d'élaborer les mesures d'atténuation ou les plans de gestion visant à minimiser les impacts des activités anthropiques sur les populations d'oiseaux.

Key Words: environmental impact assessment; juvenile survival; radio telemetry; Setophaga petechia; Yellow Warbler

\section{INTRODUCTION}

Population trajectories of many birds are particularly sensitive to variation in juvenile survival (e.g., Sergio et al. 2011, Sim et al. 2011). Juvenile birds themselves are most vulnerable during the period when they leave the nest and make the transition from being dependent on their parents to foraging independently (Naef-Daenzer and Grüebler 2016). Radio telemetry and observational studies both suggest that mortality rates are highest immediately after leaving the nest (Cox et al. 2014, Naef-Daenzer and Grüebler 2016). Consequently, the postfledging period may act as the main survival bottleneck in the first year of a bird's life (Grüebler et al. 2014).

Despite the importance of the postfledging period, studies evaluating the impact of anthropogenic activities on breeding birds typically focus on nest success or the number of young fledged. For example, Hethcoat and Chalfoun (2015) 
demonstrated that habitat loss associated with natural gas development in Wyoming decreased nest survival for Brewer's Sparrow (Spizella breweri), Sagebrush Sparrow (Artemisiospiza nevadensis), and Sage Thrasher (Oreoscoptes montanus). Similarly, Sharps et al. (2015) found that even light grazing of saltmarsh by cattle reduces nest survival rates of Common Redshank (Tringa totanus) in northwestern England. Few studies investigate anthropogenic impacts on the critical postfledging period even though anthropogenic activities can be a significant cause of postfledging mortality. For example, collisions with power lines were responsible for the vast majority $(72 \%)$ of the observed postfledging mortality of White Stork (Ciconia ciconia) in Poland, with other anthropogenic factors being responsible for an additional $16 \%$ of deaths that could be assigned a cause (Tobolka 2014).

Reservoirs are one of the major modern anthropogenic modifiers of river systems in the world (Lehner et al. 2011). These reservoirs modify the natural water flow of river systems and store water that floods large areas of land (Nilsson et al. 2005, Lehner et al. 2011). Changes in water flow and flooding regimes can have significant direct and indirect effects on avian populations. For example, management of water flow that causes water levels to rise during the breeding season can flood nests located both on the ground, e.g., Piping Plover (Charadrius melodus; Anteau et al. 2012) and Common Loon (Gavia immer; Windels et al. 2013), and in shrubs, e.g., Pygmy Cormorant (Phalacrocorax pygmeus; Nazirides and Papageorgiou 1996) and Yellow Warbler (Setophaga petechia; van Oort et al. 2015). Manipulation of flooding regimes can also cause changes in vegetation structure and composition and therefore the location and amount of available breeding habitat (Ellis et al. 2009, Hatten et al. 2010). However, no studies to date have assessed reservoir operation effects on postfledging survival of birds.

Yellow Warblers have been identified as a focal species that can be used to monitor the health of riparian habitat in the United States and Canada (Partners in Flight BC and Yukon 2003, Riparian Habitat Joint Venture 2004). Reservoir operation effects on Yellow Warblers may therefore provide an indication of their impacts on riparian habitat and other riparian obligate species. In British Columbia, Canada, reservoirs frequently fill in late spring and early summer as the snowpack melts, and rising water levels can flood active Yellow Warbler nests in shrubs on territories that were not overrun by water at the start of the breeding season (Quinlan and Green 2012, van Oort et al. 2015). However, rising water levels could also increase juvenile mortality during the postfledging period if fledglings, which fly weakly and land awkwardly, are more likely to hit the water and drown or are more vulnerable to predators.

We assess whether reservoir operations, which cause riparian habitat occupied by Yellow Warblers to be inundated by water, influence postfledging survival. Over a three-year period (2012-2014), we used radio telemetry to collect detailed data on the postfledging survival of young from territories that are either inundated by water (i.e., in which the ground below the nest was flooded at time of fledging) or unaffected by reservoir operations (i.e., in which the ground below the nest was dry at the time of fledging). We also use a 12-year data set to assess the impact of reservoir operations on the likelihood that fledglings recruit to the local breeding population.

\section{METHODS}

\section{Study species and field site location}

The Yellow Warbler is a medium-sized (9-11g) wood warbler that breeds across most of North America and winters in Mexico and Central and South America (Lowther et al. 1999). We have monitored Yellow Warblers at three study sites near Revelstoke, British Columbia, Canada since 2005 (Fig. 1a). The three sites (Drimmie Creek, Illecillawaet, and Machete Island), each approximately 30 ha (435-441 $\mathrm{m}$ a.s.1), are located in riparian habitat within or adjacent to the Upper Arrow Lakes Reservoir in the Columbia River Valley (Fig. 1b). Vegetation at these sites is dominated by black cottonwood tree stands at high elevations and willow species at lower elevations. Water levels in the reservoir fluctuate between a low water elevation of $419.65 \mathrm{~m}$ and a maximum of $440.1 \mathrm{~m}$ (Fig. 1c, d) and are controlled by operations (both for hydroelectric and flood control purposes) at Keenleyside Dam downstream and Revelstoke and Mica Dams upstream of the reservoir. Water levels typically start to rise in late May and June and peak in July, but the timing of the rise and the maximum water level in the reservoir varies across years (Green et al. 2011, van Oort et al. 2015). Yellow Warblers may therefore settle, and initiate breeding, on territories that are above the waterline, but end the season on territories that are partially or completely inundated by water.

Fig. 1. Maps and photos showing the location of Revelstoke in British Columbia (A), the three study plots (Illecillawaet, Machete Island, and Drimmie Creek) in relation to the Columbia River and the high-water mark for the Upper Arrow Lakes Reservoir (B), and a view of the Drimmie Creek study plot when water levels are low (C) and high (D).

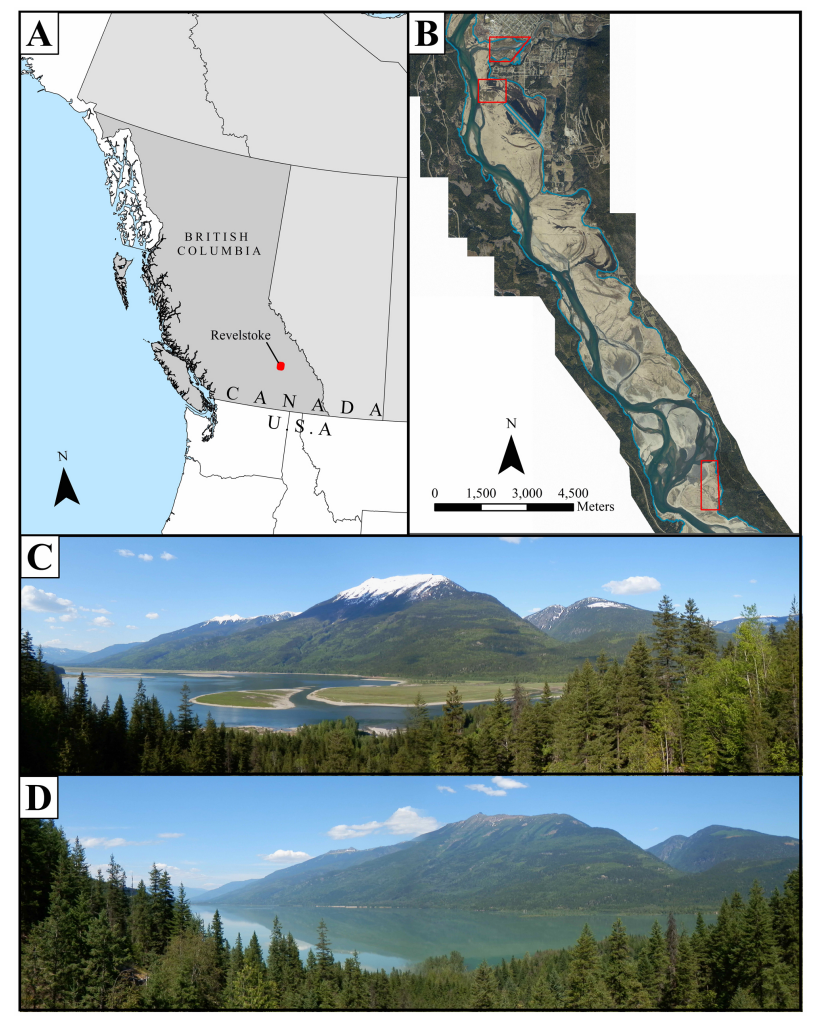




\section{General field protocols}

We collected data on the breeding biology and recruitment of Yellow Warblers over twelve years (2005-2016). In 2005-2006 and 2008-2016, we monitored all breeding pairs at the three study sites from early May, when males first started establishing territories, to late July, when the last nest fledged or failed. During 2007, data collection was limited to resighting returning adults and capturing birds that were unmarked or had one aluminum band. We typically caught and banded birds, which established territories soon after they arrived, using 6-12 m mist nets and the playback of male song and female chipping calls. We also caught incubating and provisioning females in mist nets placed close to their nests. We banded birds with a unique combination of color bands and an aluminum band issued by the Canadian Wildlife Service. We recaptured individuals banded as nestlings in previous years at all three study sites.

We attempted to find and monitor all nests built by every female during the breeding season from May to late July. We consequently monitored breeding by 19-38 females and the fate of 26-40 nests, per year. We recorded the location of each nest using a GPS unit (Garmin GPSMAP 76CSx). We subsequently monitored nests every 1-4 days to determine the date a first egg was laid, the clutch size, the date eggs hatched, and the subsequent fate of the nest. If nests were found during incubation or the nestling stage, we estimated the first egg date using the hatch date or nestling age, assuming that eggs were laid daily and incubated for 11 days. Where possible, we banded nestlings with a Canadian Wildlife Service-issued aluminum band seven days post-hatch (range six to eight days); nestlings fledge after nine days. We did not attempt to band nestlings at nests that could not be accessed safely from a canoe or with the aid of a stepladder. At this time, we also measured nestling mass to $0.1 \mathrm{~g}$ using a digital scale and tarsus length to $0.01 \mathrm{~mm}$ using digital calipers. We assumed that the number of nestlings present during this nest check was the number that fledged, if there was no evidence of predation and parents were observed feeding or defending fledged young. For each nestling that fledged, an individual nestling condition score was estimated using the residuals from a regression that modeled mass as a quadratic function of tarsus length while also controlling for significant age effects $\left(n=464, R^{2}=0.41, P<\right.$ 0.001). A quadratic function described the mass-tarsus relationship better than a linear or cubic function.

\section{Radio telemetry and postfledging survival}

We investigated postfledging survival of Yellow Warblers using radio telemetry over three years (2012-2014). We attached a Picopip Radio Tag (0.34 g; Lotek Wireless Inc., Canada) to the heaviest nestling (mean mass $=9.1 \mathrm{~g}$; range $=8.1-11.0 \mathrm{~g}$ ) in each brood on the day of banding (10-17 nests per year, total $n=39$, first nests $n=30$, renests $n=9$ ) using a loop harness (Rappole and Tipton 1991). Tags weighed $3.7 \%$ of the mean nestling mass. The heaviest nestling was on average $1.0 \mathrm{~g}$ heavier (range 0.1-4.3 $\mathrm{g}$ ) than the lightest nestling, and $0.5 \mathrm{~g}$ heavier (range 0.05-2.2 g) than the median massed nestling in the brood. The nestling was then returned to the nest along with all banded siblings. We subsequently returned each day to determine if and when young fledged. We subsequently monitored fledglings $(n=26)$ on a daily basis until the fledgling died, the battery on the tag failed, or the fledgling, siblings, and parents left the study area. We never failed to detect a fledgling with an active transmitter that was known to be in the study area. We were able to locate and therefore confirm the death of 15 fledglings. We concluded fledglings had drowned if they were found intact in the water or the transmitter was tracked to a fish. We concluded fledglings had been depredated if we found their transmitter next to a pile of feathers or a partially consumed carcass, or the transmitter was tracked to a snake. We assumed one other fledgling that could not be located had died because the parents were observed feeding the other siblings from the same nest. Radio tags had an expected life of 23 days. Two radio tags appeared to fail 10 and 12 days after they were deployed because no signal was detected although the fledglings were observed with their parents. Signals from the remaining radio tags $(n=10)$ were last detected 19-23 days after they were deployed, when fledglings were 17-21 days old. We were unable to locate these fledglings or their parents after this point and assumed that the tags had failed or the birds had left the area.

\section{Statistical analysis}

We used Cox's proportional hazard models to examine postfledging survival of fledgling Yellow Warblers $(n=26)$ that were followed using radio telemetry. In this time to event analysis, we assumed mortality had taken place on the day a fledgling was found dead $(n=15)$ or disappeared from the study area $(n=1)$. We right-censored data from fledglings that survived to 21 days postfledging or were alive when radio tags were thought to have failed; these fledglings provide information on survival/mortality up to the time of censoring. We examined if survival differed for birds fledging from inundated habitat (in which the ground below the nest was flooded at time of fledging) or from dry habitat (in which the ground below the nest was not covered by water at the time of fledging). We included two other variables that often influence postfledging survival in our analysis: nestling condition and hatch date (e.g., Green and Cockburn 2001, Mackas et al. 2010). We confirmed that a Cox's proportional hazard's model was appropriate by testing the proportional hazards assumption graphically based on the scaled Schoenfeld residuals and using the cox.zph function implemented in the R packages "survminer" (Kassambra and Kosinki 2017) and "survival” (Therneau 2015). We report the regression coefficients, hazard ratios (that give the effect size of covariates and factors), the confidence intervals of the hazard ratios, and significance of each variable in the full model.

We used generalized linear mixed effects models (GLMM) to examine the juvenile survival of Yellow Warblers that fledged between 2005 and $2015(\mathrm{n}=438)$ and recruited to the study population between 2006 and 2016. This analysis excluded any birds that were part of the radio telemetry study. Because females could produce up to eight fledglings a year and breed successfully in more than one year of the study, we included female identity as a random term. We evaluated whether recruitment (a binary variable: recruitment $=1$, otherwise $=0$ ) differed for birds fledging from inundated and dry habitat. We considered two additional explanatory variables: nestling condition and hatch date (Jan. $1=$ 1). We did not include year in this analysis because the proportion of territories that were inundated varied across years and mixed models that included year as a fixed or additional random term failed to converge. We report the regression coefficients \pm SE and Wald statistics for each term and use the full model to estimate 
the local recruitment (and 95\% CI) of a fledgling from inundated and dry habitat. All models were run in program R 3.1.1 (R Core Team 2017).

\section{RESULTS}

We attached radio tags to 39 nestlings produced by 38 different pairs of Yellow Warblers. Of these, 13 failed to fledge. We attributed all nest failure to predation. We therefore monitored the postfledging survival of 26 fledglings (15 fledglings from inundated territories and 11 fledglings from dry territories), tracking individuals for 1 to 21 days. Sixteen radio-tagged fledglings died. We attributed mortality of fledglings from inundated territories to drowning $(n=10)$ and predation $(n=1)$, and mortality of fledglings from dry territories to predation $(\mathrm{n}=$ 4) or unknown causes $(n=1)$.

Birds that fledged from nests in territories that were inundated by water had a higher risk of mortality and were less likely to survive to 21 days than those that fledged from nests in territories that were not inundated by water $(\beta=1.58$, hazard ratio $=4.87$ $\pm 0.76 \mathrm{SE}, 95 \%$ confidence interval $(\mathrm{CI})=1.11,224.18$; Wald statistic $=2.09, \mathrm{P}=0.04$; Fig. 2). All observed mortality took place in the first four days after leaving the nest. Post-fledging survival was not influenced by nestling condition $(\beta=0.94$, hazard ratio $=2.57 \pm 0.65,95 \% \mathrm{CI}=0.72,9.18$; Wald statistic $=1.45, \mathrm{P}$ $=0.15)$ or hatch date $(\beta=0.07$, hazard ratio $=1.07 \pm 0.05,95 \%$ $\mathrm{CI}=0.98,1.17$; Wald statistic $=1.50, \mathrm{P}=0.13)$. This model estimated that the probability that a fledgling (of average mass and median hatch date) survived 21 days was $0.214 \pm 0.113 \mathrm{SE}$ if their territory was inundated and $0.729 \pm 0.149$ if their territory was dry. Combined the probability of survival to 21 days was $0.387 \pm 0.102$

Fig. 2. Kaplan Meier plot showing the postfledging survival of Yellow Warblers (Setophaga petechia) from territories within the drawdown zone of the Upper Arrow Lakes Reservoir in British Columbia, Canada that were inundated (dashed line) or not inundated (solid line) by water at the time of fledging. Censored data are indicated with a $\mid$.
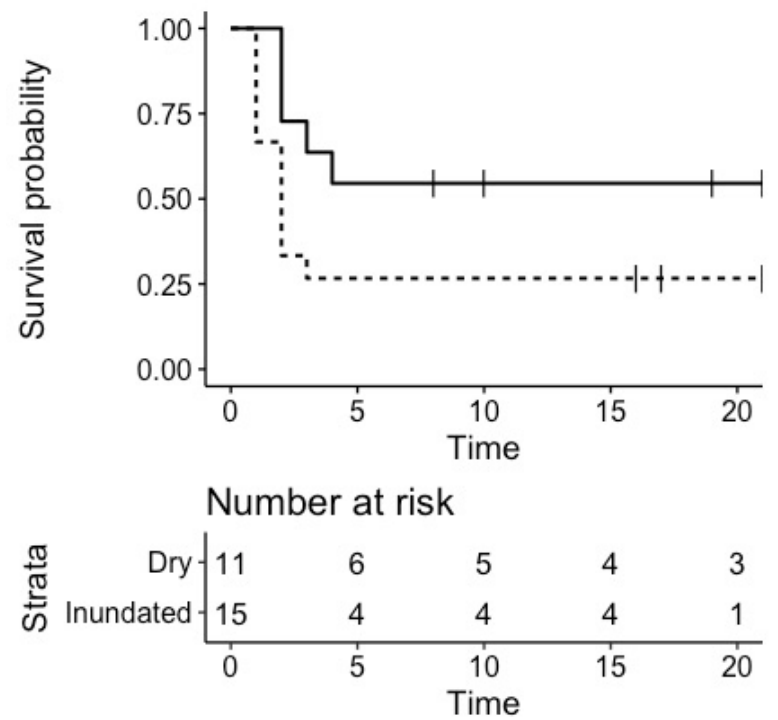

The proportion of nestlings that fledged from territories inundated by water varied across the three sites (Drimmie Creek $=0.68, \mathrm{n}=113$ fledglings; Illecillawaet $=0.47, \mathrm{n}=177$; Machete Island $=0.18, \mathrm{n}=174)$, and annually, depending on the timing and extent to which the reservoir filled in any given year (mean = $0.41 ; 2005=0,2006=0.54,2008=0.79,2009=0.25,2010=0.57$, $2011=0.35,2012=1.0,2013=0.61,2014=0.36$, and $2015=$ 0.05). The condition of nestlings from successful nests in inundated territories was no different to the condition of nestlings from successful nests in dry territories (inundated $=0.02 \pm 0.64$ $\mathrm{SD}, \mathrm{n}=191$, dry $=-0.05 \pm 0.72, \mathrm{n}=273$; GLMM with female identity as a random term, Wald statistic $=0.04, \mathrm{P}=0.84$ ).

Local recruitment was low (28 of 438 fledglings that were not involved in the radio telemetry study). Fledglings that were in good condition when banded as a 6-8 day old nestling were more likely to recruit to the local breeding population $(\beta=0.69 \pm 0.30$ SE; Wald statistic $=2.31, P=0.02 ;$ Fig. 3 ). Fledglings also tended to be more likely to recruit if they fledged in dry habitat than inundated habitat, although this effect was not statistically significant $\left(\beta_{\mathrm{WET}}=-0.85 \pm 0.49\right.$; Wald statistic $=1.72, \mathrm{P}=0.09$; Fig. 3). We found no evidence that hatch date influenced the probability of local recruitment $(\beta=0.02 \pm 0.02$; Wald statistic $=$ $0.97, \mathrm{P}=0.33$ ). For fledglings of average condition (residual from a mass-tarsus regression $=0$ ) and median hatch date, the estimated probability of recruitment for a fledgling from a dry territory was two times higher than that of a fledgling from an inundated territory $($ dry $=0.074,95 \% \mathrm{CI}=0.047,0.113$; inundated $=0.034$, $95 \% \mathrm{CI}=0.016,0.073)$.

Fig. 3. Plot illustrating the relationship between nestling condition (residuals from a mass-tarsus regression) and local recruitment of Yellow Warblers (Setophaga petechia), which fledged from territories within the drawdown zone of the Upper Arrow Lakes Reservoir in British Columbia, Canada, that were inundated (dashed line) or not inundated (solid line) by water. The shaded areas are $95 \%$ confidence bands, with the darker area showing the region in which the confidence intervals overlap. The rug plot along the $\mathrm{x}$-axis shows the distribution of the covariate values.

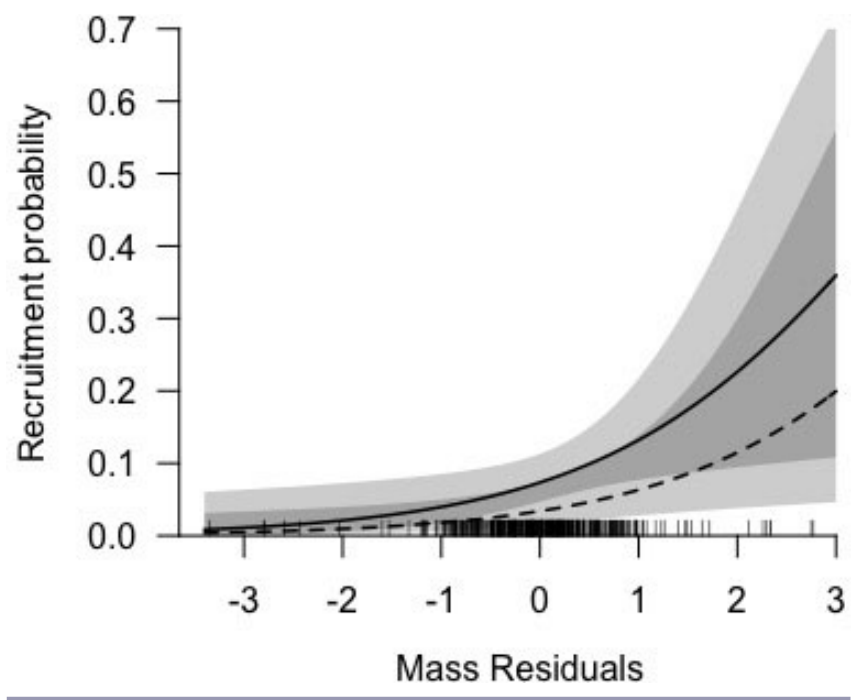




\section{DISCUSSION}

Reservoir operations, which manage water flow and storage, can influence the value of habitat within the zone that lies between the minimum and maximum elevation of the reservoir's water surface elevation because rising water levels are known to flood nests and/or reduce food availability (e.g., Wolf 1955, Espie et al. 1998, Anteau et al. 2012), and the stress on vegetation due to submersion can subsequently have an impact on the suitability of nesting habitat through effects on nest predation or food availability (Ellis et al. 2009, Hatten et al. 2010, Chapin and Paige 2013, Anteau et al. 2014). The degree to which reservoir operations have direct negative effects on nest success will depend on nest elevation and the timing of breeding relative to the operations of the reservoir (van Oort et al. 2015). We show that even for a shrub-nesting species for which reservoir operations have little impact on nest success (Quinlan and Green 2012, van Oort et al. 2015), inundation of breeding habitat can have negative effects on productivity by reducing postfledging juvenile survival.

Water levels in the Upper Arrow Lakes Reservoir in British Columbia usually begin to rise in late spring after Yellow Warblers have settled on their territories in riparian habitat within and adjacent to the reservoir. Our study suggests that reservoir operations that inundate the breeding habitat of Yellow Warblers after they have settled increases the vulnerability of fledglings during the critical postfledging period. Radio-tagged fledglings from territories inundated by water were twice as likely to die in the three weeks after fledging than fledglings from drier territories, with most mortality attributed to drowning. We acknowledge that this component of the study was restricted to 26 birds and that the radio tags were not randomly deployed because they were placed on the heaviest nestling in a brood to minimize the percentage mass gained when carrying a radio tag. This decision could bias our results if heavier nestlings cannot fly as far or are less capable of outmaneuvering a predator (Adriaensen et al. 1998, Gow and Wiebe 2014) without hitting the ground or water. However, the radio-tagged nestling was only slightly heavier than the median-massed nestling in a brood, we controlled for the condition of the nestling in our analysis, and the estimated hazard ratio suggested that inundation increased the risk of mortality. We also found that banded fledglings from territories inundated by water tended to be less likely to recruit locally than fledglings from drier territories. This result is consistent with our radio-telemetry data and could arise because birds that fledge in territories that are inundated by water have lower survival during the postfledging period. However, this pattern could also arise because birds that fledge in territories inundated by water are less likely to return to our study site. Some studies have found that information gained on the breeding grounds at the end of the season can influence the subsequent settlement decisions of migratory birds (e.g., Nocera et al. 2006, but see Harrison et al. 2009). The consistent pattern in two independent datasets, nevertheless, provides evidence that reservoir operations may have negative effects on Yellow Warblers during the postfledging period.

To meet environmental objectives, the management of water levels within reservoirs will need to involve trade-offs and will be constrained by social and economic objectives including the supply of water (for agriculture, industries, and households), flood management, recreation, and power generation. Trade-offs are also expected across environmental objectives. Water management to reduce potential impacts on shrub-nesting species like Yellow Warblers, may also have unintended consequences for restoration or conservation of other components of riparian ecosystems. As an example, if managed water levels in the Upper Arrow Lakes Reservoir were delayed by 2 weeks, then when reservoir water levels typically reached the elevation that supports shrubs, the percentage of Yellow Warblers that fledged prior to the flooding of their habitat would increase from 6 to $68 \%$. However, delays in when the reservoir fills could increase the number of ground-nesting birds, such as Savannah Sparrows Passerculus sandwichensis, that attempt to breed in grass habitat rather than elsewhere at lower elevations within the reservoir footprint, and these could lose their nests when water levels rise. Management actions that aim to mitigate the potential impacts of reservoirs should therefore consider the consequences for multiple rather than a single species within the riparian ecosystem.

Juvenile birds are thought to be particularly vulnerable in the period immediately after they leave the nest (Lloyd and Martin 2016, NaefDaenzer and Grüebler 2016). We found that Yellow Warblers were vulnerable just before and just after fledging, with all the postfledging mortality taking place in the first four days after fledging. Predators were likely directly responsible for all mortality late in the nestling period and approximately a third of the postfledging mortality. However, predators may also have been indirectly responsible for some of the mortality that occurred as a result of drowning, for example, if fledglings drowned while attempting to escape a predator. The postfledging mortality we observed is consistent with other studies that have demonstrated that mortality rates are highest in the first day after fledging (e.g., Tome and Denac 2012) and then steadily decrease (Naef-Danzer and Grüebler 2016), with most mortality occurring in the first week (Lloyd and Martin 2016). The estimated postfledging survival to 21 days of Yellow Warblers is also similar to those estimated for the closely related Hooded Warbler, Setophaga citrina, (0.23, Rush and Stutchbury 2008; 0.57 Eng et al. 2011) and within the range of estimates obtained from 31 studies on songbirds in North and South America (range = 0.23 - 0.87; Cox et al. 2014).

For altricial birds, postfledging survival to independence and recruitment is frequently modulated by nestling mass/condition and the seasonal timing of fledging (e.g., Green and Cockburn 2001, Mackas et al. 2010, Naef-Daenzer et al. 2001). We show that nestling condition influences the probability that Yellow Warbler fledglings recruit to the local breeding population. The absence of nestling condition effects on the postfledging survival of radiotagged birds could be a consequence of choosing to only add radio tags to large nestlings. Potentially, habitat inundation could have greater effects on the postfledging survival of lighter or less developed nestlings that are less capable of flying. Nestling condition is known to vary with a variety of environmental characteristics and parental traits (e.g., habitat type, Mackas et al. 2010; parental age, Hegyi et al. 2006). Reservoir operations that flood riparian habitat dramatically alter the habitat used by breeding birds and might be expected to reduce food availability and nestling provisioning rates, at least for some species. We found, however, that reservoir operations had little influence on nestling condition. Reservoir operation effects on postfledging survival and local recruitment in Yellow Warblers are therefore not explained or exacerbated by their impact on the amount of available foraging habitat (but see Espie et al. 1998 for a counter example). 
Avian Conservation and Ecology 13(1): 12

Population models demonstrate that in birds with moderate to high reproductive output, factors influencing nest success and juvenile survival will have a large effect on population growth rates (Sæther and Bakke 2000, Clark and Martin 2007). Recent studies suggest that juvenile survival can also play an important role in the population dynamics of long-lived species (e.g., Black Kite Milvus migrans, Sergio et al. 2011). Studies assessing the impact of anthropogenic activities on breeding birds that ignore the postfledging period may consequently underestimate any negative effects on bird populations. Previous work examining reservoir operation effects on ground-nesting Piping Plovers shows that rising water levels can both reduce nest success and the subsequent survival of their mobile precocial chicks (Espie et al. 1998). Our work shows that reservoir operations can also have negative effects on shrub-nesting species that breed in riparian habitat within the drawdown zone. Despite the difficulties of tracking the fate of young birds after they have left the nest, we believe additional research on the critical postfledging period would provide insights on management decisions aimed at minimizing the impact of anthropogenic activities on bird populations.

Responses to this article can be read online at: http://www.ace-eco.org/issues/responses.php/1190

\section{Acknowledgments:}

We thank Doug Adama and Ed Hill who were instrumental in the early years of this project. Funding for this work came from BC Hydro Water License Requirements and an NSERC Discovery grant to DJG. We are indebted to Sam Quinlan, Christine Rock, Michaela Martin, and Michal Pavlik for providing Yellow Warbler data from 2005 to 2016 and to the many field technicians who have been involved with our study. Ryan Gill and Kyle Tonnesen contributed the images and photos for Figure 1. We are also grateful for the insightful comments from three anonymous reviewers that helped improve this manuscript.

\section{LITERATURE CITED}

Adriaensen, F., A. A. Dhondt, S. Van Dongen, L. Lens, and E. Matthysen. 1998. Stabilizing selection in Blue Tit fledging mass in the presence of Sparrowhawks. Proceedings of the Royal Society of London, Series B, Biological Sciences 265:1011-1016. http://dx. doi.org/10.1098/rspb.1998.0392

Anteau, M. J., T. L. Shaffer, M. H. Sherfy, M. A. Sovada, J. H. Stucker, and M. T. Wiltermuth. 2012. Nest survival of Piping Plovers at a dynamic reservoir indicates an ecological trap for a threatened population. Oecologia 170:1167-1179. http://dx.doi. org/10.1007/s00442-012-2384-y

Anteau, M. J., M. T. Wiltermuth, M. H. Sherfy, and T. L. Shaffer. 2014. Measuring and predicting abundance and dynamics of habitat for Piping Plovers on a large reservoir. Ecological Modelling 272:16-27. http://dx.doi.org/10.1016/j.ecolmodel.2013.08.020

Chapin, D. M., and D. K. Paige. 2013. Response of delta vegetation to water level changes in a regulated mountain lake,
Washington State, USA. Wetlands 33:431-444. http://dx.doi. org/10.1007/s13157-013-0401-5

Clark, M. E., and T. E. Martin. 2007. Modeling tradeoffs in avian life history traits and consequences for population growth. Ecological Modelling 209:110-120. http://dx.doi.org/10.1016/j. ecolmodel.2007.06.008

Cox, W. A., F. R. Thompson, III, A. S. Cox, and J. Faaborg. 2014. Post-fledging survival in passerine birds and the value of postfledging studies to conservation. Journal of Wildlife Management 78:183-193. http://dx.doi.org/10.1002/jwmg.670

Ellis, L. A., S. D. Stump, and D. M. Weddle. 2009. Southwestern Willow Flycatcher population and habitat response to reservoir inundation. Journal of Wildlife Management 73:946-954. http:// dx.doi.org/10.2193/2008-297

Eng, M. L., B. J. M. Stutchbury, D. M. Burke, and K. A. Elliott. 2011. Influence of forest management on pre- and post-fledging productivity of a Neotropical migratory songbird in a highly fragmented landscape. Canadian Journal of Forest Research 41:2009-2019. http://dx.doi.org/10.1139/x11-119

Espie, R. H. M., P. C. James, and R. M. Brigham. 1998. The effects of flooding on Piping Plover Charadrius melodus reproductive success at Lake Diefenbaker, Saskatchewan, Canada. Biological Conservation 86:215-222. http://dx.doi.org/10.1016/S0006-3207 (98)00001-9

Gow, E. A., and K. L. Wiebe. 2014. Determinants of parental care and offspring survival during the post-fledging period: males care more in species with partially reversed sex roles. Oecologia 175:95-104. http://dx.doi.org/10.1007/s00442-014-2890-1

Green, D. J., and A. Cockburn. 2001. Post-fledging care, philopatry and recruitment in Brown Thornbills. Journal of Animal Ecology 70:505-514. http://dx.doi.org/10.1046/ j.1365-2656.2001.00503.x

Green, D. J., K. B. Loukes, M. W. Pennell, J. Jarvis, and W. E. Easton. 2011. Reservoir water levels do not influence daily mass gain of warblers at a riparian stopover site. Journal of Field Ornithology 82:11-24. http://dx.doi.org/10.1111/j.1557-9263.2010.00303. $\mathrm{x}$

Grüebler, M. U., F. Korner-Nievergelt, and B. Naef-Daenzer. 2014. Equal nonbreeding period survival in adults and juveniles of a long-distant migrant bird. Ecology and Evolution 4:756-765. http://dx.doi.org/10.1002/ece3.984

Harrison M. L., D. J. Green, and P. G. Krannitz. 2009. Conspecifics influence the settlement decisions of male Brewer's Sparrows at the northern edge of their range. Condor 111:722-729. http://dx.doi.org/10.1525/cond.2009.090126

Hatten, J. R., E. H. Paxton, and M. K. Sogge. 2010. Modeling the dynamic habitat and breeding population of Southwestern Willow Flycatcher. Ecological Modelling 221:1674-1686. http:// dx.doi.org/10.1016/j.ecolmodel.2010.03.026

Hegyi, G., B. Rosivall, and J. Török. 2006. Paternal age and offspring growth: separating the intrinsic quality of young from rearing effects. Behavioral Ecology and Sociobiology 60:672-682. http://dx.doi.org/10.1007/s00265-006-0211-3 
Hethcoat, M. G., and A. D. Chalfoun. 2015. Towards a mechanistic understanding of human-induced rapid environmental change: a case study linking energy development, nest predation and predators. Journal of Applied Ecology 52:1492-1499. http:// dx.doi.org/10.1111/1365-2664.12513

Kassambara, A., and M. Kosinski. 2017. Survminer: drawing survival curves using 'ggplot2'. R package version 0.4.0.999. R Foundation for Statistical Computing, Vienna, Austria. [online] URL: http:/www.sthda.com/english/rpkgs/survminer/

Lehner, B., C. R. Liermann, C. Revenga, C. Vörösmarty, B. Fekete, P. Crouzet, P. Döll, M. Endejan, K. Frenken, J. Magome, C. Nilsson, J. C. Robertson, R. Rödel, N. Sindorf, and D. Wisser. 2011. High-resolution mapping of the world's reservoirs and dams for sustainable river-flow management. Frontiers in Ecology and the Environment 9:494-502. http://dx.doi.org/10.1890/100125

Lloyd, P., and T. E. Martin. 2016. Fledgling survival increases with development time and adult survival across north and south temperate zones. Ibis 158:135-143. http://dx.doi.org/10.1111/ ibi. 12325

Lowther, P. E., C. Celada, N. K. Klein, C. C. Rimmer, and D. A. Spector. 1999. Yellow Warbler (Setophaga petechia). Number 454 in A. Poole, editor. The birds of North America online. Cornell Lab of Ornithology, Ithaca, New York, USA. [online] URL: http://bna.birds.cornell.edu/bna/species/454

Mackas, R. H., D. J. Green, I. B. J. Whitehorne, E. N. Fairhurst, H. A. Middleton, and C. A. Morrissey. 2010. Altitudinal migration in American Dippers (Cinclus mexicanus): do migrants produce higher quality offspring? Canadian Journal of Zoology 88:369-377. http://dx.doi.org/10.1139/Z10-013

Nazirides, T., and N. Papageorgiou. 1996. The breeding biology of Pygmy Cormorants (Phalacrocorax pygmeus), a vulnerable bird species, at Lake Kerkini, northern Greece. Colonial Waterbirds 19:219-223. http://dx.doi.org/10.2307/1521965

Naef-Daenzer, B., and M. U. Grüebler. 2016. Post-fledging survival of altricial birds: ecological determinants and adaptation. Journal of Field Ornithology 87:227-250. http://dx. doi.org/10.1111/jofo. 12157

Naef-Daenzer, B., F. Widmer, and M. Nuber. 2001. Differential post-fledging survival of Great and Coal Tits in relation to their condition and fledging date. Journal of Animal Ecology 70:730-738. http://dx.doi.org/10.1046/j.0021-8790.2001.00533.x

Nilsson, C., C. A. Reidy, M. Dynesius, and C. Revenga. 2005. Fragmentation and flow regulation of the world's large river systems. Science: 308:405-408. http://dx.doi.org/10.1126/science.1107887

Nocera, J. J., G. J. Forbes, and L.-A. Giraldeau. 2006. Inadvertent social information in breeding site selection of natal dispersing birds. Proceedings of the Royal Society of London, Series B, Biological Sciences 273:349-355. http://dx.doi.org/10.1098/ rspb.2005.3318

Partners in Flight British Columbia and Yukon. 2003. Canada's Great Basin landbird conservation plan. Version 1.0. Partners in Flight British Columbia and Yukon, Delta, British Columbia, Canada. [online] URL: https://www.partnersinflight.org/wpcontent/uploads/2017/03/Partners-in-Flight-BCYK-CGBLCP_v1-0final-Dec-2003.pdf
Quinlan, S. P., and D. J. Green. 2012. Riparian habitat disturbed by reservoir management does not function as an ecological trap for the Yellow Warbler (Setophaga petechia). Canadian Journal of Zoology 90:320-328. http://dx.doi.org/10.1139/z11-138

R Core Team. 2017. R: a language and environment for statistical computing. The R Foundation for Statistical Computing, Vienna, Austria. [online] URL: https://www.R-project.org/

Rappole, J., and A. Tipton. 1991. New harness design for attachment of radio transmitters to small passerines. Journal of Field Ornithology 62:335-337. [online] URL: https://sora.unm. edu/sites/default/files/journals/jfo/v062n03/p0335-p0337.pdf

Riparian Habitat Joint Venture. 2004. The riparian bird conservation plan: a strategy for reversing the decline of riparian associated birds in California. Version 2.0. California Partners in Flight, California, USA. [online] URL: https://www.prbo.org/ calpif/pdfs/riparian_v-2.pdf

Rush, S. A., and B. J. M. Stutchbury. 2008. Survival of fledgling Hooded Warblers (Wilsonia citrina) in small and large forest fragments. Auk 125:183-191. http://dx.doi.org/10.1525/ auk.2008.125.1.183

Sæther, B.-E., and Ø. Bakke. 2000. Avian life history variation and contribution of demographic traits to the population growth rate. Ecology 81:642-653. http://dx.doi.org/10.1890/0012-9658 (2000)081[0642:ALHVAC]2.0.CO;2

Sergio, F., G. Tavecchia, J. Blas, L. Lopéz, A. Tanferna, and F. Hiraldo. 2011. Variation in age-structured vital rates of a longlived raptor: implications for population growth. Basic and Applied Ecology 12:107-115. http://dx.doi.org/10.1016/j.baae.2010.11.004

Sharps, E., J. Smart, M. W. Skov, A. Garbutt, and J. G. Hiddink. 2015. Light grazing of saltmarshes is a direct and indirect cause of nest failure in Common Redshank Tringa totanus. Ibis 157:239-249. http://dx.doi.org/10.1111/ibi.12249

Sim, I. M. W., G. W. Rebecca, S. C. Ludwig, M. C. Grant, and J. M. Reid. 2011. Characterizing demographic variation and contributions to population growth rate in a declining population. Journal of Animal Ecology 80:159-170. http://dx.doi.org/10.1111/ j.1365-2656.2010.01750.x

Therneau, T. 2015. A package for survival analysis in $S$. Version 2.38. The R Foundation for Statistical Computing, Vienna, Austria. [online] URL: https://CRAN.R-project.org/package= survival

Tobolka, M. 2014. Importance of juvenile mortality in birds' population: early post-fledging mortality and causes of death in White Stork Ciconia ciconia. Polish Journal of Ecology 62:807-813. http://dx.doi.org/10.3161/104.062.0403

Tome, D., and D. Denac. 2012. Survival and development of predator avoidance in the post-fledging period of the Whinchat (Saxicola rubetra): consequences for conservation measures. Journal of Ornithology 153:131-138. http://dx.doi.org/10.1007/ s10336-011-0713-2

van Oort, H., D. J. Green, M. Hepp, and J. M. Cooper. 2015. Do fluctuating water levels alter nest survivorship in reservoir shrubs? Condor 117:376-385. http://dx.doi.org/10.1650/CONDOR-14-154.1 
Windels, S. K., E. A. Beever, J. D. Paruk, A. R. Brinkman, J. E. Fox, C. C. Macnulty, D. C. Evers, L. S. Siegel, and D. C. Osborne. 2013. Effects of water-level management on nesting success of Common Loons. Journal of Wildlife Management 77:1626-1638. http://dx.doi.org/10.1002/jwmg.608

Wolf, K. 1955. Some effects of fluctuating and falling water levels on waterfowl production. Journal of Wildlife Management 19:13-23. http://dx.doi.org/10.2307/3797548 